\title{
Short-Term Audiological Results of Diode Laser in Comparison with Manual Perforation in Stapes Surgery
}

\author{
Rogerio Hamerschmidt ${ }^{1,2}$ Stephanie Sbizera Saab ${ }^{1}$ Bettina Carvalho ${ }^{1}$ Carolina do Carmo ${ }^{2}$ \\ ${ }^{1}$ Department of ENT, Instituto Paranaense de Otorrinolaringologia \\ (IPO), Curitiba, PR, Brazil \\ 2 Department of ENT, Universidade Federal do Paraná, Curitiba, PR, \\ Departmento de Otorrinolaringologia, Universidade Federal do \\ Paraná, rua Francisco Rocha 1.640, Curitiba, PR, 80730-390, Brazil \\ (e-mail: stephanie.saab@hotmail.com).
}

Int Arch Otorhinolaryngol 2018;22:119-124.

\begin{abstract}
Introduction Diode laser is a new alternative in stapes surgery for otosclerosis. The present study is the first to compare the short-term results of the surgery performed using diode laser to those obtained through the conventional fenestration technique. Objective To use audiometry to establish a comparative analysis between the functional results obtained through surgery for otosclerosis using diode laser and the conventional technique.

Method Audiometric evaluation of 12 patients submitted to stapes surgery for otosclerosis, using diode laser or conventional fenestration by needle and drills, between 2014 and 2015. Each group was composed of 6 patients. Pre and postoperative measures were compared for three months in both groups. The speech recognition threshold, the air and bone conduction threshold, as well as the gap between them at $500 \mathrm{~Hz}, 1 \mathrm{KHz}, 2 \mathrm{KHz}$ and $4 \mathrm{KHz}$ were measured.

Results Significant difference in bone conduction and SRT was observed when compared post- and preoperative results in the diode group. However diode and conventional technique groups presented significant differences in air conduction and air-bone gap, suggesting that both can provide functional improvement.

Keywords

- otosclerosis

- stapes surgery

- diode laser

Conclusion Laser stapedotomy is a safe technique with good results. Both laser surgery and the conventional technique have improved the hearing of patients with a discreet advantage for the diode laser. Further prospective and randomized clinical trials are required to disclose all possible benefits of the stapes surgery using diode laser.
\end{abstract}

\section{Introduction}

Otosclerosis is a disease characterized by alterations in the composition and architecture of the temporal bone. Hearing loss is the most common complaint, and it occurs mainly due to ankylosis of the stapes footplate. However, the disease can be more complex and involve the whole otic capsule.

received

September 14, 2016

accepted

March 9, 2017

published online

May 17, 2017 10.1055/s-0037-1602703. ISSN 1809-9777.
Replacing the stapes for prosthesis can surgically treat this disorder. This procedure is named stapedectomy.

Despite being a safe procedure, stapes surgery for otosclerosis may cause permanent sensorineural hearing loss in a small percentage of patients.

The first stapedectomy on a patient with otosclerosis was performed and described in 1956 by John Shea. ${ }^{1}$ Since then,

Copyright $\odot 2018$ by Thieme Revinter Publicações Ltda, Rio de Janeiro, Brazil

\section{License terms}

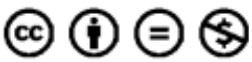


professionals aim to improve the surgical technique as well as search for better materials.

Throughout the years, the footplate perforation technique ranged from the use of micro instruments to the use of micro drills and, more recently, laser. The main advantage of the laser is its precision and low risk of footplate mobilization, since in this technique there is no direct manipulation. ${ }^{2-4}$

The conventional technique is simple, and, therefore, it is still widely used. Nevertheless, the use of laser in stapedectomy is increasing gradually, since it causes less damage to the middle and inner ears. ${ }^{5,6}$

In 1980, Perkins utilized for the first time the argon laser. ${ }^{7}$ Thenceforth, several types of laser were suggested, but each one has specific characteristics and risks. ${ }^{8,9}$

The use of diode laser was reported for the first time in 2000 with the expectation that it would become an efficient and low-cost instrument. ${ }^{9}$ The diode laser is a semiconductor that provides infrared radiation that provide high energy powered by little energy. ${ }^{8}$

Besides that, the contact of the diode laser fibers with the target structure provides more precision. The diameter of the fiber can be adjusted according to the procedure and the absorption spectrum produces the ability to clot. These characteristics make the diode laser an effective tool in otologic surgery. ${ }^{10}$

Wavelengths of $800 \mathrm{~nm}$ and 1,064 $\mathrm{nm}$ are the most used. When compared with the potassium titanyl phosphate (KTP) laser, the diode laser presents high absorption in water. However, when compared with the erbium-doped yttrium aluminum garnet (Er-YAG) laser, the diode laser shows low absorption in water and high absorption in pigmented tissues. After stapes footplate fenestration, surplus energy is absorbed by the perilymph and by the pigmented region of neuroendothelium - less than KTP. ${ }^{8}$

The diode laser is already extensively used in the clinical practice; however, there are few studies reporting its use in stapes surgery.

\section{Objective}

The purpose of this study is to establish a comparative analysis between hearing results achieved through diode laser and conventional fenestration technique in stapes surgery, using audiometry.

\section{Patients and Methods}

The present study obtained the approval of the Ethics Committee (CAAE 48732015300005529), and data from the patients submitted to surgery between 2014 and 2015 were collected.

Twelve patients from both genders and aged between 18 and 70 years with no prior history of otologic surgery were selected.

In this cross-sectional study, the patients were divided into two surgical groups: the one submitted to stapes surgery using diode laser technique and the one submitted to the conventional technique.
Before the surgery, all patients signed a consent form and were informed about the surgical techniques and the risks of the procedure. Computed tomography of the temporal bone, as well as pure tone and vocal audiometry (using an AD 229 audiometer, Interacoustics, Middelfart, Denmark), were also performed before the surgery.

In the audiometry evaluation, the tone used for most of the patients was continuous, except in cases of patients with tinnitus, for whom the tone was warble. The method was descending. The phone used for the search of air thresholds was the TDH39P, and the vibrator used for the search of tonal thresholds by bone was the B71 (Middle Fort, Denmark).

\section{Surgical Technique}

\section{Diode Laser}

The procedure was performed through endaural access, while the patients were sedated and under local anesthesia.

The diode laser was applied over the stapes footplate through a $0.4 \mathrm{~mm}$ fiber coupled to a hand piece. The laser was shot at $2 \mathrm{~W}$. This system is safe due to its thermal sensor, and it automatically turns off once it reaches critical temperatures.

\section{Conventional Technique}

The conventional technique consists of perforating the stapes footplate using a needle or coupling the drill to a micro drill when necessary to size the fenestra properly. The same surgical access and type of prosthesis were used in both surgical approaches.

\section{Audiometry}

The patients were submitted to audiometry exams prior to the surgery and on the following three months. The speech recognition threshold, the air and bone conduction threshold, as well as the gap between them at $500 \mathrm{~Hz}, 1 \mathrm{KHz}, 2 \mathrm{KHz}$ and $4 \mathrm{KHz}$ were measured. These measurements are presented in decibels $(\mathrm{dB})$.

\section{Results}

The results were divided into four parts: bone conduction $(B C)$; air conduction (AC); air-bone gap (ABG); and speech recognition thresholds (SRTs). In each part, the differences between the groups (diode versus conventional) and also between the periods (pre- and post-operative) were considered. The multivariate analysis of variance (MANOVA), the analysis of variance (ANOVA) and the $t$-test with Bonferroni correction were applied according to each situation. For all cases, values of $p<0.05$ were considered as the cut-off point.

\section{Bone Conduction (BC) Comparative}

-Table 1 shows the results of the MANOVA tests that verified simultaneously the presence of differences between groups and periods for all frequencies. No significant difference was found between the groups ( $p=0.453$ ), while evidence of a significant difference between the periods was observed for at least one frequency ( $p=0.001)$. 
Table 1 MANOVA test results for bone conduction

\begin{tabular}{|l|l|l|c|}
\hline & DF & F-value & $p$-value \\
\hline Group & 1 & 1.033 & 0.453 \\
\hline Period & 1 & 13.39 & 0.001 \\
\hline
\end{tabular}

Abbreviations: DF: degrees of freedom; Manova, multivariate analysis of variance.

Notes: Comparison between periods (pre and post-operative) and groups (diode laser and conventional technique). Values of $p<0.05$ indicate significant difference.

In - Table 2, the mean and the standard deviation for both groups for each period and for each frequency are presented, as well as the $p$-value of the $t$-test with Bonferroni correction. Examining each frequency, it is possible to state once again that there was no significant difference between the groups. It is not possible to allege that both groups are equal, but only that there is no evidence of difference. That is an important point to highlight, because different results could be observed in a study with a different sample size or different experimental conditions.

- Table 3 shows a comparison of the mean between the periods, and also presents the mean, standard deviation and $p$-value of the $t$-test with Bonferroni correction. It should be noted that there was a significant difference between the pre- and post-operative periods in the conventional technique group for the frequency of $1 \mathrm{KHz}(p<0.05)$. For other frequencies, this difference was not evident.

\section{Air Conduction (AC) Comparative}

For the $\mathrm{AC}$, the MANOVA test presents evidence of a significant difference between periods for at least one frequency. Between the groups, there was no evidence of significant differences.

Higher mean values were observed for the preoperative period in comparison with the post-operative period, and for

Table 2 Mean (standard deviation) for the pre- and post-operative periods for both groups and at all frequencies for bone conduction

\begin{tabular}{|c|c|c|c|}
\hline & Conventional & Diode & $p$-value \\
\hline Pre- & & & \\
\hline $500 \mathrm{~Hz}$ & $24.17(12.42)$ & $26.67(10.8)$ & 0.718 \\
\hline $1 \mathrm{KHz}$ & $32.5(10.37)$ & $28.33(13.29)$ & 0.558 \\
\hline $2 \mathrm{KHz}$ & $35(14.14)$ & $34.17(11.58)$ & 0.913 \\
\hline $4 \mathrm{KHz}$ & $40(16.43)$ & $44.17(17.15)$ & 0.677 \\
\hline Post- & & & \\
\hline $500 \mathrm{~Hz}$ & $21.67(8.76)$ & $23.33(8.16)$ & 0.74 \\
\hline $1 \mathrm{KHz}$ & $25.83(11.14)$ & $23.33(10.8)$ & 0.701 \\
\hline $2 \mathrm{KHz}$ & $28.33(17.51)$ & $29.17(17.15)$ & 0.935 \\
\hline $4 \mathrm{KHz}$ & $30(12.25)$ & $32.5(8.8)$ & 0.693 \\
\hline
\end{tabular}

Notes: The $p$-value corresponds to the $t$-test with Bonferroni correction for each frequency comparing both groups. Values of $p<0.05$ indicate significant difference.
Table 3 Mean (standard deviation) for the pre- and post-operative periods for both groups and at all frequencies for bone conduction

\begin{tabular}{|c|c|c|c|}
\hline & Pre- & Post & $p$-value \\
\hline Diode & & & \\
\hline $500 \mathrm{~Hz}$ & $26.67(10.8)$ & $23.33(8.16)$ & 0.175 \\
\hline $1 \mathrm{KHz}$ & $28.33(13.29)$ & $23.33(10.8)$ & 0.111 \\
\hline $2 \mathrm{KHz}$ & $34.17(11.58)$ & $29.17(17.15)$ & 0.203 \\
\hline $4 \mathrm{KHz}$ & $44.17(17.15)$ & $32.5(8.8)$ & 0.11 \\
\hline Conventional & & & \\
\hline $500 \mathrm{~Hz}$ & $24.17(12.42)$ & $21.67(8.76)$ & 0.203 \\
\hline $1 \mathrm{KHz}$ & $32.5(10.37)$ & $25.83(11.14)$ & 0.001 \\
\hline $2 \mathrm{KHz}$ & $35(14.14)$ & $28.33(17.51)$ & 0.14 \\
\hline $4 \mathrm{KHz}$ & $40(16.43)$ & $30(12.25)$ & 0.093 \\
\hline
\end{tabular}

Notes: The $p$-value corresponds to the $t$-test with Bonferroni correction for each frequency comparing both groups. Values of $p<0.05$ indicate no significant difference..

each frequency, the mean values for both groups were very similar.

- Table 4 presents a comparison between both groups for each period and frequency.

For both groups, the comparison between periods indicates significant differences for practically all frequencies. Both groups also presented reductions on the observed values (-Table 5).

\section{Comparison between Different Hearing Thresholds for Bone Conduction and Air Conduction (Gap)}

For the air-bone gap, there are multiple answers; therefore, the MANOVA test was used. The test presented evidence of significant differences between periods for at least one frequency, and no evidence between the groups.

Higher mean values were observed at the preoperative period in comparison with the post-operative one. It should

Table 4 Mean (standard deviation) at pre- and post-operative periods for both groups and all frequencies for air conduction

\begin{tabular}{|c|c|c|c|}
\hline & Conventional & Diode & $p$-value \\
\hline Pre- & & & \\
\hline $500 \mathrm{~Hz}$ & $58.33(19.92)$ & $54.17(18.55)$ & 0.716 \\
\hline $1 \mathrm{KHz}$ & $55.83(23.54)$ & $51.67(22.29)$ & 0.759 \\
\hline $2 \mathrm{KHz}$ & $54.17(22)$ & $48.33(22.95)$ & 0.663 \\
\hline $4 \mathrm{KHz}$ & $59.17(12.42)$ & $57.5(16.05)$ & 0.845 \\
\hline Post- & & & \\
\hline $500 \mathrm{~Hz}$ & $35.83(15.94)$ & $28.33(8.76)$ & 0.336 \\
\hline $1 \mathrm{KHz}$ & $34.17(12.42)$ & $28.33(6.83)$ & 0.337 \\
\hline $2 \mathrm{KHz}$ & $36.67(14.02)$ & $34.17(13.2)$ & 0.757 \\
\hline $4 \mathrm{KHz}$ & $40(17.89)$ & $40.83(12.42)$ & 0.927 \\
\hline
\end{tabular}


122 Short-Term Audiological Results of Diode Laser vs Manual Perforation Hamerschmidt et al.

Table 5 Mean (standard deviation) at pre- and post-operative periods for both groups at all frequencies for air conduction

\begin{tabular}{|c|c|c|c|}
\hline & Pre- & Post- & $p$-value \\
\hline Diode & & & \\
\hline $500 \mathrm{~Hz}$ & $54.17(18.55)$ & $28.33(8.76)$ & 0.013 \\
\hline $1 \mathrm{KHz}$ & $51.67(22.29)$ & $28.33(6.83)$ & 0.024 \\
\hline $2 \mathrm{KHz}$ & $48.33(22.95)$ & $34.17(13.2)$ & 0.051 \\
\hline $4 \mathrm{KHz}$ & $57.5(16.05)$ & $40.83(12.42)$ & 0.028 \\
\hline Conventional & & & \\
\hline $500 \mathrm{~Hz}$ & $58.33(19.92)$ & $35.83(15.94)$ & 0.027 \\
\hline $1 \mathrm{KHz}$ & $55.83(23.54)$ & $34.17(12.42)$ & 0.023 \\
\hline $2 \mathrm{KHz}$ & $54.17(22)$ & $36.67(14.02)$ & 0.017 \\
\hline $4 \mathrm{KHz}$ & $59.17(12.42)$ & $40(17.89)$ & 0.005 \\
\hline
\end{tabular}

also be noted that each period presented similar values for both groups at each frequency.

- Table 6 shows a comparison between groups for each period and frequency. The MANOVA test has already indicated that there is no evidence of differences at any frequency. Despite that, the $p$-value of each comparison is presented, and none of them were $<0.05$.

The comparison between the pre- and post-operative periods shows significant differences at $500 \mathrm{~Hz}$ for both groups, and at $4 \mathrm{KHz}$ for the conventional technique group. Due to the variance present in our study, in addition to a reduced sample, evidences of difference are not observed at some frequencies. Nevertheless, both groups presented a reduction in the post-operative period when compared with the preoperative period. In order to obtain these values, the $t$-test with Bonferroni correction was applied. (-Table 7).

\section{Speech Recognition Threshold (SRT) Comparative}

- Table 8 shows the results of this test. A difference between periods for at least one group can be observed, but no evidence of difference was found between the groups.

Table 6 Mean (standard deviation) at pre- and post-operative periods in both groups at all frequencies for gap

\begin{tabular}{|c|c|c|c|}
\hline & Conventional & Diode & $p$-value \\
\hline Pre- & & & \\
\hline $500 \mathrm{~Hz}$ & $34.17(16.56)$ & $27.5(11.73)$ & 0.44 \\
\hline $1 \mathrm{KHz}$ & $23.33(13.66)$ & $23.33(12.11)$ & 1 \\
\hline $2 \mathrm{KHz}$ & $19.17(12.01)$ & $14.17(12.01)$ & 0.487 \\
\hline $4 \mathrm{KHz}$ & $19.17(10.68)$ & $13.33(15.38)$ & 0.463 \\
\hline Post- & & & \\
\hline $500 \mathrm{~Hz}$ & $14.17(14.97)$ & $5(5.48)$ & 0.189 \\
\hline $1 \mathrm{KHz}$ & $8.33(7.53)$ & $5(6.32)$ & 0.426 \\
\hline $2 \mathrm{KHz}$ & $8.33(8.16)$ & $5(7.75)$ & 0.485 \\
\hline $4 \mathrm{KHz}$ & $10(8.37)$ & $8.33(7.53)$ & 0.724 \\
\hline
\end{tabular}

Table 7 Mean (standard deviation) for pre- and post-operative periods, both groups and all frequencies for gap

\begin{tabular}{|c|c|c|c|}
\hline & Pre- & Post- & p-value \\
\hline Diode & & & \\
\hline $500 \mathrm{~Hz}$ & $27.5(11.73)$ & $5(5.48)$ & 0.019 \\
\hline $1 \mathrm{KHz}$ & $23.33(12.11)$ & $5(6.32)$ & 0.056 \\
\hline $2 \mathrm{KHz}$ & $14.17(12.01)$ & $5(7.75)$ & 0.261 \\
\hline $4 \mathrm{KHz}$ & $13.33(15.38)$ & $8.33(7.53)$ & 0.229 \\
\hline Conventional & & & \\
\hline $500 \mathrm{~Hz}$ & $34.17(16.56)$ & $14.17(14.97)$ & 0.031 \\
\hline $1 \mathrm{KHz}$ & $23.33(13.66)$ & $8.33(7.53)$ & 0.083 \\
\hline $2 \mathrm{KHz}$ & $19.17(12.01)$ & $8.33(8.16)$ & 0.157 \\
\hline $4 \mathrm{KHz}$ & $19.17(10.68)$ & $10(8.37)$ & 0.028 \\
\hline
\end{tabular}

Notes: The $p$-value corresponds to the $t$-test with Bonferroni correction for each frequency comparing both groups. Values of $p<0.05$ indicate no significant difference.

It can be noticed that both groups presented similar values for each period, with the post-operative period presenting lower values than the preoperative period.

- Table 9 demonstrates the comparison between periods for each group. Once more, the $t$-test with Bonferroni correction was applied. A significant difference was observed in the diode group, while the conventional technique group presented no difference. It is noteworthy that a reduction during the post-operative period was observed in both groups.

\section{Discussion}

No statistically significant difference was observed in both groups regarding bone conduction $(\mathrm{BC})$. Some difference would be expected while comparing pre- and post-operative values. However, only the diode group presented a statistically significant difference. The numeric differences observed must be considered in a clinical approach of data.

Table 8 Mean (standard deviation) at pre- and post-operative periods for both groups at all frequencies for SRT

\begin{tabular}{|l|c|c|c|}
\hline & Conventional & Diode & $p$-value \\
\hline Pre- & $51(16.36)$ & $50.83(19.34)$ & 0.988 \\
\hline Post- & $37(14.83)$ & $34.17(13.93)$ & 0.752 \\
\hline
\end{tabular}

Abbreviation: SRT, speech recognition threshold.

Table 9 Mean (standard deviation) for pre- and post-operative periods in both groups at all frequencies for SRT

\begin{tabular}{|l|c|c|c|}
\hline & Pre- & Post- & $p$-value \\
\hline Diode & $50.83(19.34)$ & $34.17(13.93)$ & 0.028 \\
\hline Conventional & $51(16.36)$ & $37(14.83)$ & 0.073 \\
\hline
\end{tabular}

Abbreviation: SRT, speech recognition threshold. 
But according to the statistical comparison, only the diode group presented a change after the treatment.

A comparison between the groups did not show significant differences at any period. The first comparison between the groups at the pre-operative period must not show any difference, because otherwise the post-operative treatment could be compromised.

The comparative study on AC did not show any difference between groups either. A significant difference between periods was observed in both groups, indicating that the post-operative values were significantly lower than those before the treatment.

No significant difference was observed between the groups in the gap comparison. On comparing post-operative and preoperative values, a significant difference was observed in both groups, indicating that they are able to reduce gap values.

The SRT analysis did not show significant differences between the groups, although significant differences at the post-operative period were only observed for the diode group. It is noteworthy that the values were reduced after treatment in both groups, and we consider these differences clinically important, but a statistical difference between the pre- and post-operative periods can only be stated for the diode group. In this case, we can notice that, even without a statistical difference, the diode group had slightly lower values than the conventional treatment group.

This is an original study, since there is no other research in the literature that compares the short-term results of diode laser with the conventional manual perforation technique.

All patients who participated in this study were admitted and operated under sedation and local anesthesia, and were discharged at the same day, with no complaints of dizziness or uneasiness. Therefore, a comparison of the post-operative complaints did not seem relevant, since it would return an extremely reduced index.

Laser tissue ablation occurs by absorption of light energy generating heat. This absorption depends on the wavelength of the light and the optical properties of the tissue. ${ }^{11,12}$

Many authors believe that the laser enhances the surgeon's precision because it facilitates the removal of the superstructures of the stapes, reducing mechanical and vibratory trauma with an easier perforation of the footplate and exposure of the oval window niche. ${ }^{13,14}$

The diode laser is a national low-cost technology and an alternative to energy sources more commonly widespread internationally. It is also a useful tool for stapedotomy for otosclerosis with a wavelength of $980 \mathrm{~nm}$. The mechanical, thermal and acoustic effects are limited and safe. ${ }^{8}$

Poletti et $\mathrm{a} 1{ }^{15}$ believe that the use of a high-power diode laser for short exposure periods can be considered safe, precise and very useful for otosclerosis surgery. In their study, they used the laser at $40 \mathrm{~W}$ and an exposure time of 60 minutes. According to our observations, the diode laser is precise, comfortable and safe when a potency of $2 \mathrm{~W}$ is applied through a $0.4 \mathrm{~mm}$ optic fiber.

In comparison with the carbon dioxide $\left(\mathrm{CO}_{2}\right)$ and the erbium-doped yttrium aluminum garnet (Er-YAG) lasers, the diode presents higher water absorption in pigmented tissues and low water absorption. When compared with the potassium titanyl phosphate (KTP) laser, the diode laser shows higher water absorption. After stapes footplate fenestration, surplus energy is absorbed by the perilymph and by the pigmented region of the neuroendothelium. ${ }^{8}$

Nguyen et $\mathrm{al}^{10}$ observed no difference on the incidence of complications between surgeries performed using the diode laser and the micro drill technique. According to the authors, the main advantage of performing stapedotomy using the laser technique is the reduced number of fractures on the stapes footplate in comparison with the micro drill technique. These data are relevant because the increasing use of laser can assure good results with lower indexes of floating footplates. Nevertheless, the general results obtained by L. Fang et al suggest that the laser technique offers better hearing results when compared with the conventional technique. The authors highlighted that there are not sufficient data to assess the results of the different laser subgroups ${ }^{6}$

Wegner et al performed a review of the literature comparing the results and surgical complications of surgeries performed using laser or the conventional manual technique, and concluded that there was no evidence that one technique was superior to the other in terms of hearing results and dizziness. However, there is an increased risk of fracture of the footplate and sensorineural hearing loss when using micro instruments and the micro drill (manual technique). ${ }^{16}$

It is known that the inner ear is damaged by the heating of its fluids. Periods of prolonged exposure to high temperatures are associated with tinnitus, dizziness and hearing loss. ${ }^{17}$ Furthermore, it is suggested that mechanical trauma causes hearing loss as a result of the formation of sound pressure. However, the thermal and mechanical effects of the diode laser are minimal, and that is an advantage it has over the other lasers. ${ }^{8}$

In a study performed by Feng et al, there were no statistically significant differences in the audiometric exams of patients from the diode group and the Feng micro drill group. ${ }^{18}$ This result is similar to the one obtained in our study, but the use of laser presented better results for the SRT.

In the present study, all patients presented preserved anatomy, but an assessment of the use of laser in patients with compromised anatomy (such as floating footplates) is required in order to fully understand the benefits of using the laser technique in these cases. Moreover, the reduced sample size and the lack of long-term follow-up can be considered biases of this study.

\section{Conclusion}

Stapes surgery using diode laser is a safe technique that presents good results. Both the diode laser and the conventional technique, using a needle, a drill and a micro drill, have improved the hearing of the patients, with a slight advantage for the laser technique. Further prospective and randomized 
124 Short-Term Audiological Results of Diode Laser vs Manual Perforation Hamerschmidt et al.

clinical trials are required to disclose all possible benefits of stapedotomy using diode laser.

\section{References}

1 Shea JJJ Jr. Fenestration of the oval window. Ann Otol Rhinol Laryngol 1958;67(04):932-951

2 Coker NJ, Ator GA, Jenkins HA, Neblett CR. Carbon dioxide laser stapedotomy: a histopathologic study. Am J Otolaryngol 1986; 7(04):253-257

3 Häusler R, Messerli A, Romano V, Burkhalter R, Weber HP, Altermatt HJ. Experimental and clinical results of fiberoptic argon laser stapedotomy. Eur Arch Otorhinolaryngol 1996;253(4-5): 193-200

4 Jovanovic S, Anft D, Schönfeld U, Berghaus A, Scherer H. Influence of $\mathrm{CO} 2$ laser application to the guinea-pig cochlea on compound action potentials. Am J Otol 1999;20(02):166-173

5 Kamalski DMA, Wegner I, Tange RA, et al. Outcomes of different laser types in laser-assisted stapedotomy: a systematic review. Otol Neurotol 2014;35(06):1046-1051

6 Fang L, Lin H, Zhang T-Y, Tan J. Laser versus non-laser stapedotomy in otosclerosis: a systematic review and meta-analysis. Auris Nasus Larynx. 2014;41(04):337-342

7 Perkins RC. Laser stepedotomy for otosclerosis. Laryngoscope 1980;90(02):228-240

8 Kamalski DM, de Boorder T, Bittermann AJ, Wegner I, Vincent R, Grolman W. Capturing thermal, mechanical, and acoustic effects of the diode $(980 \mathrm{~nm})$ laser in stapedotomy. Otol Neurotol 2014; 35(06):1070-1076
9 Poe DS. Laser-assisted endoscopic stapedectomy: a prospective study. Laryngoscope 2000;110(5 Pt 2, Suppl 95)1-37

10 Nguyen Y, Grayeli AB, Belazzougui R, et al. Diode laser in otosclerosis surgery: first clinical results. Otol Neurotol 2008;29(04): 441-446

11 Giering K, Minet O, Lamprecht I, Muller G. Review of thermal properties of bi- ological tissues. In: Muller G, Roggan A, eds. Laser-induced interstitial thermo- therapy. Bellingham, WA: SPIE Press; 1995:45-65

12 Ahrar K, Gowda A, Javadi S, et al. Preclinical assessment of a 980-nm diode laser ablation system in a large animal tumor model. J Vasc Interv Radiol 2010;21(04):555-561

13 Beatty TW, Haberkamp TJ, Khafagy YW, Bresemann JA. Stapedectomy training with the carbon dioxide laser. Laryngoscope 1997;107(11 Pt 1):1441-1444

14 Lippy WH, Battista RA, Berenholz L, et al. Twenty-year review of revision stapedectomy. Otol Neurotol 2003;24:560-566

15 Poletti AM, Miceli S, Rossi V, Di Pietro S, Tosi G, Colombo G. The "One Shot" Diode Laser Stapedotomy. Photomed Laser Surg 2015; 33(12):598-603

16 Wegner I, Kamalski DM, Tange RA, et al. Laser versus conventional fenestration in stapedotomy for otosclerosis: a systematic review. Laryngoscope 2014;124(07):1687-1693

17 Noyes WS, McCaffrey TV, Fabry DA, Robinette MS, Suman VJ. Effect of temperature elevation on rabbit cochlear function as measured by distortion-product otoacoustic emissions. Otolaryngol Head Neck Surg 1996;115(06):548-552

18 Feng XH, Xie NP, Lin F, et al. [Therapeutic effects of small fenestra stapedotomy with semiconductor diode laser: a comparison with microdrill]. Nan Fang Yi Ke Da Xue Xue Bao 2008;28(08): 1391-1393 